\title{
lodine deficiency among Belgian pregnant women not fully corrected by iodine-containing multivitamins: a national cross-sectional survey
}

\author{
Stefanie Vandevijvere ${ }^{1 *}$, Sihame Amsalkhir ${ }^{2}$, Ahmed Bensouda Mourri ${ }^{2}$, Herman Van Oyen ${ }^{1}$ and \\ Rodrigo Moreno-Reyes ${ }^{2}$ \\ ${ }^{1}$ Department of Public Health and Surveillance, Scientific Institute of Public Health, J.Wytsmanstraat 14, \\ 1050 Brussels, Belgium \\ ${ }^{2}$ Department of Nuclear Medicine, Hôpital Erasme, Université Libre de Bruxelles, Route de Lennik 808, 1070 Brussels, \\ Belgium
}

(Submitted 12 March 2012 - Final revision received 23 August 2012 - Accepted 29 August 2012 - First published online 19 October 2012)

\begin{abstract}
Low iodine intake during pregnancy may cause thyroid dysfunction in pregnant women and their newborn. In the present study, iodine status among a nation-wide representative sample of Belgian pregnant women in the first and third trimester of pregnancy was determined, and determinants of iodine status were assessed 1 year after the introduction of bread fortified with iodised salt. The women were selected according to a multistage proportionate-to-size sampling design. Urine samples were collected and a general questionnaire was completed face to face with the study nurse. The median urinary iodine concentration (UIC) among pregnant women $(n 1311)$ was $124 \cdot 1 \mu \mathrm{g} / \mathrm{l}$ and $122.6 \mu \mathrm{g} / \mathrm{g}$ creatinine when corrected for urinary creatinine. The median UIC in the first trimester (118.3 $\mathrm{g} / \mathrm{l})$ was significantly lower than that in the third trimester $(131.0 \mu \mathrm{g} / \mathrm{l})$ but significantly higher than among non-pregnant women (84.8 $\mu \mathrm{g} / \mathrm{l})$. Iodine-containing supplement intake was reported by $60.8 \%$ of the women and $57.4 \%$ of the women took this supplement daily. The risk of iodine deficiency was significantly higher in younger women, in women not taking iodine-containing supplements, with low consumption of milk and dairy drinks and during autumn. Women with a higher BMI had a higher risk of iodine deficiency but the risk was lower in women who reported alcohol consumption. The median UIC during pregnancy indicates iodine deficiency in Belgium and some women are at a higher risk of deficiency. The current low iodine intake in women of childbearing age precludes the correction of iodine deficiency in pregnant women supplemented with multivitamins containing $150 \mu \mathrm{g}$ iodine as recommended.
\end{abstract}

Key words: Iodine deficiency: Belgium: Pregnant women

Pregnancy induces fundamental changes in thyroid function and iodine metabolism leading to thyroid stimulation ${ }^{(1)}$. The stimulation of the thyroid gland during pregnancy stems from the rise of oestrogen concentrations resulting in an increase of serum thyroxin-binding globulin, an increase in the renal clearance of iodide, the iodide transfer to the fetus, the direct stimulation of the thyroid by the human chorionic gonadotrophin and finally resulting in changes in the peripheral metabolism of maternal thyroid hormones under the influence of the placenta. Iodine-sufficient pregnant women meet their thyroid hormone requirement by increasing the thyroid iodide intake, maintaining a plentiful store of iodine in the thyroid. In iodine-deficient women, this adaptive mechanism fails to maintain adequate iodine stores, which can lead to thyroid dysfunction in the pregnant women and their newborn. Some studies have suggested that mild iodine deficiency during pregnancy may impair neuropsychological development $^{(2)}$ and psychomotor ${ }^{(3)}$ development in the offspring, preventing them from reaching their full intellectual potential $^{(4)}$. However, the impact of mild-to-moderate maternal iodine deficiency on cognition of the offspring is still unclear as few controlled intervention studies have measured long-term clinical outcomes ${ }^{(5)}$. Correction of mild-to-moderate iodine deficiency via supplementation in primary school children was found to improve cognitive and motor function ${ }^{(6)}$.

Despite a worldwide successful implementation of iodine supplementation programmes over the last decades, iodine deficiency remains a public health problem in Europe ${ }^{(7,8)}$. According to the WHO, the median urinary iodine concentration (UIC) among pregnant women within the range $150-249 \mu \mathrm{g} / 1$ is indicative of iodine sufficiency ${ }^{(9)}$. Although, since 2003, the number of European countries in which

Abbreviation: UIC, urinary iodine concentration.

*Corresponding author: S. Vandevijvere, fax +32 26 425410, email stefanie.vandevijvere@wiv-isp.be 
iodine deficiency remains a public health problem decreased from twenty-three to fourteen ${ }^{(10)}$, it is a matter of concern that iodine deficiency has reappeared in countries thought to have sufficient iodine intake, such as the $\mathrm{UK}^{(11)}$. Several surveys have indicated that Belgium is affected by mild iodine deficiency, and that this represents a substantial economic burden to the Belgian healthcare system ${ }^{(12-14)}$. Consequently, optimising iodine intake was chosen as a priority in the nutritional policy of the Belgian Ministry of Health.

An agreement was signed between the bakery sector and the Ministry of Health in April 2009, to encourage the fortification of bread with iodised salt (voluntary fortification) ${ }^{(15)}$.

A recent national survey on iodine status in Belgian schoolaged children has shown a median UIC of $113 \cdot 1$ and $84 \cdot 8 \mu \mathrm{g} / 1$ among their mothers, indicating iodine sufficiency among the children and suggesting that the voluntary fortification of bread with iodised salt may have contributed to the optimisation of iodine intake in school-aged children but not in the adult population $^{(16)}$.

The aim of this first national representative study was to assess iodine status among pregnant women in Belgium during the first and third trimester of pregnancy, and to examine the determinants of iodine status in a mild iodine-deficient area, 1 year after the introduction of bread fortification with iodised salt.

\section{Methods}

\section{Sampling}

The target population of the survey comprised all pregnant women in Belgium during the first or third trimester of pregnancy in the period of the survey from September 2010 to June 2011. The women were selected according to a multistage proportionate-to-size stratified sampling design. Because some population-based data suggest that the prevalence of iodine deficiency is higher in the south than in the north of the country ${ }^{(17,18)}$, the hospitals were stratified by region. A thirty-cluster survey was performed in both regions with at least twenty women per cluster, as recommended ${ }^{(19)}$ A sample size calculation based on an estimated $70 \%$ prevalence of UIC $<150 \mu \mathrm{g} / \mathrm{l}^{(13)}$, a $95 \%$ CI for the true prevalence of UIC $<150 \mu \mathrm{g} / 1$, a design effect of 2 and an absolute precision of $5 \%$ resulted in a sample size of 645 women per region (1290 women, in total) or about twenty-two women per hospital: eleven in the first trimester and eleven in the third trimester of pregnancy.

In each region, the hospitals were ordered by province and size based on the number of deliveries during the past year and sixty clusters of four hospitals were selected using systematic sampling while accounting for the number of deliveries in order to have enough replacement hospitals in case

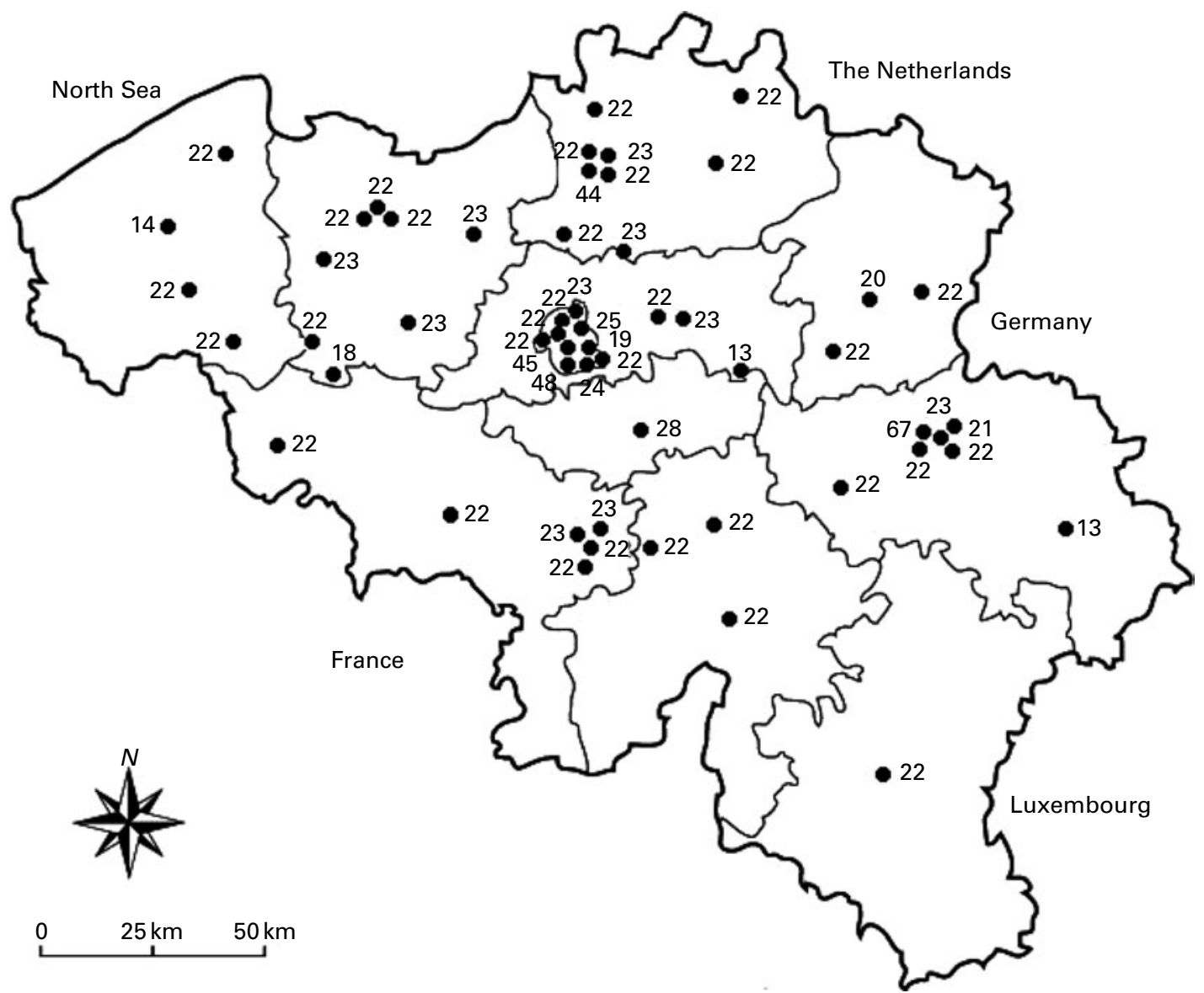

Fig. 1. Geographical distribution of the fifty-five hospitals visited in Belgium and the number of pregnant women $(n 1311)$ investigated by site (national survey on the iodine status of pregnant women, Belgium 2010-11). 
hospitals refused to participate. Of these sixty clusters, thirty clusters were randomly selected and within each cluster, the first hospital was invited to participate. In each hospital, all gynaecologists were invited to participate in order to level out a possible gynaecologist effect.

\section{Data collection}

The present study was conducted according to the guidelines laid down in the Declaration of Helsinki and all procedures involving human subjects were approved by the medical ethical committee of the Erasme Hospital in Brussels. Written and verbal informed consent was obtained from all pregnant women. The fieldwork took place between September 2010 and June 2011. Urine samples were collected and a general questionnaire about sociodemographic and socio-economic characteristics, smoking and alcohol-drinking behaviour, thyroid diseases, use of iodine-containing supplements, consumption frequency of seaweed, fish and seafood, eggs, milk and dairy drinks, yoghurt, cottage cheeses and cheeses, consumption quantity of fish and seafood, milk and dairy drinks, yoghurt, cottage cheeses and cheeses, usual number of slices of bread consumed per $\mathrm{d}$ and use of iodised household salt was completed face to face with the study nurse. For one hospital (n 23 women), certain questions (mainly nationality, ethnicity and education level) needed to be omitted from the questionnaire upon decision of the ethical committee of this particular hospital. BMI was obtained from weight and height recorded by the gynaecologist during the first consultation for women in both the first and third trimester of pregnancy.

There were sixteen categories to report education level and they were recoded into six categories: secondary education or lower; higher education; university or higher; other education; no education; not known.

\section{Analysis of samples}

All urine samples were frozen and kept at $-80^{\circ} \mathrm{C}$ until analysis. UIC were measured in duplicate at Erasme Hospital using a modification of the Sandell-Kolthoff reaction with spectrophotometric detection ${ }^{(20)}$. The sensitivity of the assay was $12 \mu \mathrm{g} / \mathrm{l}$. The Erasme laboratory participated successfully in the Program to Ensure the Quality of Urinary Iodine Procedures of the US Centers for Disease Control and Prevention ${ }^{(21)}$. Urinary creatinine was determined by a colorimetric method based on the Jaffe reaction ${ }^{(22)}$.

\section{Statistical analyses}

Statistical analyses were carried out using STATA 10.1 (StataCorp). As UIC is not normally distributed, non-parametric methods were used. Differences in UIC between regions, trimesters and age groups were explored using the twosample Wilcoxon rank-sum test or the Kruskal-Wallis equality-of-populations rank test. The odds of having a UIC lower than $150 \mu \mathrm{g} / \mathrm{l} v$. an optimal iodine status were estimated by multiple logistic regression while controlling for age, trimester of pregnancy, region, BMI, smoking behaviour, alcohol consumption, use of iodine-containing food supplements, use of iodised household salt, bread consumption, fish consumption, milk and dairy drink consumption, education level, ethnicity and parity.

\section{Results}

Among the 1311 pregnant women participating in the survey, 214 were from Brussels, 640 from Flanders and 455 from Wallonia (Fig. 1). For two women, the region was missing. The mean age of women was 28.5 (SD 5.1) years ( $n$ 1305) and was similar in all three regions. For 1307 women, a general questionnaire was available. The mean BMI of women was $24 \cdot 4$ (SD $5 \cdot 1) \mathrm{kg} / \mathrm{m}^{2}$. More than $20 \%$ of the women in the sample were from non-Caucasian origin and more than $50 \%$ of the women included had a lower education level. Of all women included, $15 \%$ smoked during pregnancy and $12 \%$ reported having drunk alcohol during pregnancy (Table 1 ).

There were 640 women in the first trimester of pregnancy while 666 were in the third trimester of pregnancy and two were in the second trimester of pregnancy. For $41.7 \%$ of the

Table 1. Characteristics of the pregnant women included in the study (Belgian national survey on micronutrient status in pregnant women, 2010-11)

(Number of participants and percentages, $n$ 1311)

\begin{tabular}{|c|c|c|}
\hline Characteristics & $\%$ & $n$ \\
\hline \multicolumn{3}{|l|}{ BMI $\left(\mathrm{kg} / \mathrm{m}^{2}\right)$} \\
\hline Underweight & $5 \cdot 7$ & 73 \\
\hline Healthy weight & $59 \cdot 2$ & 763 \\
\hline Overweight & $22 \cdot 1$ & 285 \\
\hline Obese & $13 \cdot 1$ & 169 \\
\hline \multicolumn{3}{|l|}{ Ethnicity } \\
\hline White/Caucasian & $73 \cdot 6$ & 965 \\
\hline Asiatic & 2.5 & 33 \\
\hline African (black) & 4.9 & 64 \\
\hline North African & 13.4 & 176 \\
\hline Hispanic & 0.9 & 12 \\
\hline Not known & 4.7 & 61 \\
\hline \multicolumn{3}{|l|}{ Education level } \\
\hline Secondary education or lower & 54.5 & 715 \\
\hline Higher education & $27 \cdot 2$ & 357 \\
\hline University or higher & 14.9 & 195 \\
\hline Other education & 0.2 & 3 \\
\hline No education & 0.7 & 9 \\
\hline Not known & $2 \cdot 4$ & 32 \\
\hline \multicolumn{3}{|l|}{ Smoking } \\
\hline Yes & $16 \cdot 8$ & 220 \\
\hline During past 4 weeks & $15 \cdot 4$ & 202 \\
\hline No & 82.9 & 1087 \\
\hline Not known & 0.3 & 4 \\
\hline \multicolumn{3}{|l|}{ Drinking alcohol } \\
\hline Yes & $20 \cdot 4$ & 267 \\
\hline During past 4 weeks & 11.5 & 151 \\
\hline No & 78.5 & 1029 \\
\hline Not known & $1 \cdot 1$ & 15 \\
\hline Supplement use during pregnancy & $76 \cdot 2$ & 999 \\
\hline lodine supplements & $60 \cdot 8$ & 797 \\
\hline Daily iodine supplements & 57.4 & 746 \\
\hline lodine supplements during the first trimester & $50 \cdot 9$ & 326 \\
\hline Daily iodine supplements during the first trimester & $49 \cdot 0$ & 312 \\
\hline lodine supplements during the third trimester & $70 \cdot 4^{\star}$ & 469 \\
\hline Daily iodine supplements during the third trimester & $65 \cdot 7^{*}$ & 432 \\
\hline
\end{tabular}

${ }^{*}$ Values were significantly different from those of the first trimester $(P<0.001)$. 
Table 2. Distribution of urinary iodine concentrations (UIC, $\mu \mathrm{g} / \mathrm{l}$ and $\mu \mathrm{g} / \mathrm{g}$ creatinine) in pregnant women ( $n$ 1299) (national study on iodine status among pregnant women in Belgium, 2010)

(Mean values and standard deviations; medians, inter quartile ranges (IQR), percentages and $95 \%$ confidence intervals)

\begin{tabular}{|c|c|c|c|c|c|c|c|c|c|c|}
\hline & \multicolumn{2}{|c|}{ All women } & \multicolumn{2}{|c|}{ Wallonia } & \multicolumn{2}{|c|}{ Flanders } & \multicolumn{2}{|c|}{ First trimester } & \multicolumn{2}{|c|}{ Third trimester } \\
\hline & Mean & SD & Mean & SD & Mean & SD & Mean & SD & Mean & SD \\
\hline$n$ & \multicolumn{2}{|c|}{1299} & \multicolumn{2}{|c|}{452} & \multicolumn{2}{|c|}{633} & \multicolumn{2}{|c|}{631} & \multicolumn{2}{|c|}{663} \\
\hline Age (years) & 28.5 & $5 \cdot 1$ & $27 \cdot 9$ & 5.5 & $28 \cdot 8$ & $4 \cdot 7$ & $28 \cdot 3$ & $5 \cdot 1$ & $28 \cdot 8^{\star \star \star}$ & $5 \cdot 1$ \\
\hline Gestational weeks & $22 \cdot 2$ & 12.5 & $22 \cdot 1$ & $12 \cdot 8$ & $22 \cdot 4$ & $12 \cdot 3$ & 9.9 & $2 \cdot 8$ & $34 \cdot 1$ & 3.6 \\
\hline \multicolumn{11}{|l|}{ UIC $(\mu \mathrm{g} / \mathrm{l})$} \\
\hline Median & \multicolumn{2}{|c|}{$124 \cdot 1$} & \multicolumn{2}{|c|}{$117 \cdot 2$} & \multicolumn{2}{|c|}{$125 \cdot 1$} & \multicolumn{2}{|c|}{$118 \cdot 3$} & \multicolumn{2}{|c|}{$131 \cdot 0^{\star \star \star}$} \\
\hline IQR & \multicolumn{2}{|c|}{$72 \cdot 6-212 \cdot 8$} & \multicolumn{2}{|c|}{$67 \cdot 8-199 \cdot 6$} & \multicolumn{2}{|c|}{$72 \cdot 9-204 \cdot 6$} & \multicolumn{2}{|c|}{$69 \cdot 6-192 \cdot 5$} & \multicolumn{2}{|c|}{$74 \cdot 5-235 \cdot 3$} \\
\hline $95 \% \mathrm{Cl}$ & \multicolumn{2}{|c|}{$118 \cdot 3,131 \cdot 0$} & \multicolumn{2}{|c|}{$108 \cdot 7,129 \cdot 2$} & \multicolumn{2}{|c|}{$117 \cdot 2,134 \cdot 2$} & \multicolumn{2}{|c|}{$110 \cdot 0,126 \cdot 8$} & \multicolumn{2}{|c|}{$123 \cdot 3,140 \cdot 0$} \\
\hline$<150 \mu \mathrm{g} / \mathrm{l}$ & \multicolumn{2}{|c|}{$59 \cdot 3$} & \multirow{2}{*}{\multicolumn{2}{|c|}{$\begin{array}{l}63 \cdot 7 \\
40 \cdot 2\end{array}$}} & \multicolumn{2}{|c|}{58.4} & \multicolumn{2}{|c|}{$62 \cdot 2$} & \multicolumn{2}{|c|}{56.5} \\
\hline$<100 \mu \mathrm{g} / \mathrm{l}$ & \multicolumn{2}{|c|}{$37 \cdot 8$} & & & \multirow{2}{*}{\multicolumn{2}{|c|}{$\begin{array}{l}37 \cdot 6 \\
10 \cdot 5\end{array}$}} & & & & \\
\hline$<50 \mu \mathrm{g} / \mathrm{l}$ & & & \multicolumn{2}{|c|}{$13 \cdot 4$} & & & & & & \\
\hline UIC:creatinine $(\mu \mathrm{g} / \mathrm{g}$ & ine) & & & & & & & & & \\
\hline Median & & & & & & & & & & \\
\hline IQR & $75 \cdot$ & & 70 . & & 82. & & $71 \cdot 1$ & & 81.9 & \\
\hline $\begin{array}{l}95 \% \mathrm{Cl} \\
\text { lodine supplements }\end{array}$ & 115 & & 102 & $5 \cdot 3$ & 115 & 9.5 & $99 \cdot 2$ & & 129 . & \\
\hline lodine supplements ( & & & & & & & & & & \\
\hline Before pregnancy & & & & & & & & & & \\
\hline First trimester & & & & & & & & & & \\
\hline
\end{tabular}

${ }^{\star \star \star}$ Mean values were significantly different from the first trimester $(P<0.001)$.

$\dagger \dagger \dagger$ Mean values were significantly different from Wallonia $(P=0.040)$.

$\ddagger \ddagger \ddagger$ Mean values were significantly different from Wallonia $(P<0.001)$.

women, this was their first pregnancy, and $45 \cdot 6 \%$ of the women had been pregnant before. For the other women, this information was missing. Nearly $4.0 \%$ of the women had had a miscarriage at least once. Interestingly, $77.6 \%$ of the women stated that their pregnancy was planned. Of all women included, thirty-six $(2 \cdot 7 \%)$ reported suffering from a thyroid disease: eighteen suffered from hypothyroidism; four from hyperthyroidism; six from goitre or nodules; one from thyroiditis; the disease was unspecified for the other women.

The median UIC among the pregnant women was $124 \cdot 1 \mu \mathrm{g} / \mathrm{l}$ and even lower when corrected for urinary creatinine $(122.6 \mu \mathrm{g} / \mathrm{g}$ creatinine). Of all pregnant women included, $59 \cdot 3 \%$ had a UIC below $150 \mu \mathrm{g} / 1,37 \cdot 8 \%$ had a UIC below $100 \mu \mathrm{g} / \mathrm{l}$ while $18.4 \%$ had a UIC above $249 \mu \mathrm{g} / 1$ and $3.7 \%$ of the women had a UIC above $500 \mu \mathrm{g} / \mathrm{l}$. The median UIC in the first trimester of pregnancy was significantly lower than that in the third trimester $(118.3$ and $131.0 \mu \mathrm{g} / \mathrm{l}$, respectively). These differences were even more pronounced when the UIC was corrected for urinary creatinine (106.2 and $139.6 \mu \mathrm{g} / \mathrm{g}$ creatinine, respectively; Table 2). Compared with pregnant women, the median UIC in women of childbearing age was significantly lower, even when the UIC was corrected for urinary creatinine (Fig. 2).

The median UIC in Flanders and Wallonia were not significantly different. However, the UIC values corrected for urinary creatinine were significantly lower in Wallonia than in Flanders ( 112.0 and $124.2 \mu \mathrm{g} / \mathrm{g}$ creatinine, respectively; Table 2). The median UIC was highest in the oldest age group ( $>31$ years, $132.2 \mu \mathrm{g} / \mathrm{l}$ ), and lowest in the youngest age group $(\leq 26$ years, $116 \mu \mathrm{g} / \mathrm{l})(P<0 \cdot 001)$.

Most of the women reported taking iodine-containing multivitamins during pregnancy (Table 1). The percentage of women taking iodine supplements was significantly higher in the third than in the first trimester of pregnancy. The majority of women started taking iodine supplements during pregnancy and only $12 \%$ of them started taking iodine supplements before pregnancy (Table 2). There were no differences among the regions in the use of iodine-containing supplements and the frequency of intake; however, in Flanders, the percentage of women starting to take iodine supplements before pregnancy was significantly higher than in Wallonia.

Of all women included in the survey, $87 \cdot 2 \%$ reported using non-iodised salt or sea salt, while $11.2 \%$ reported using

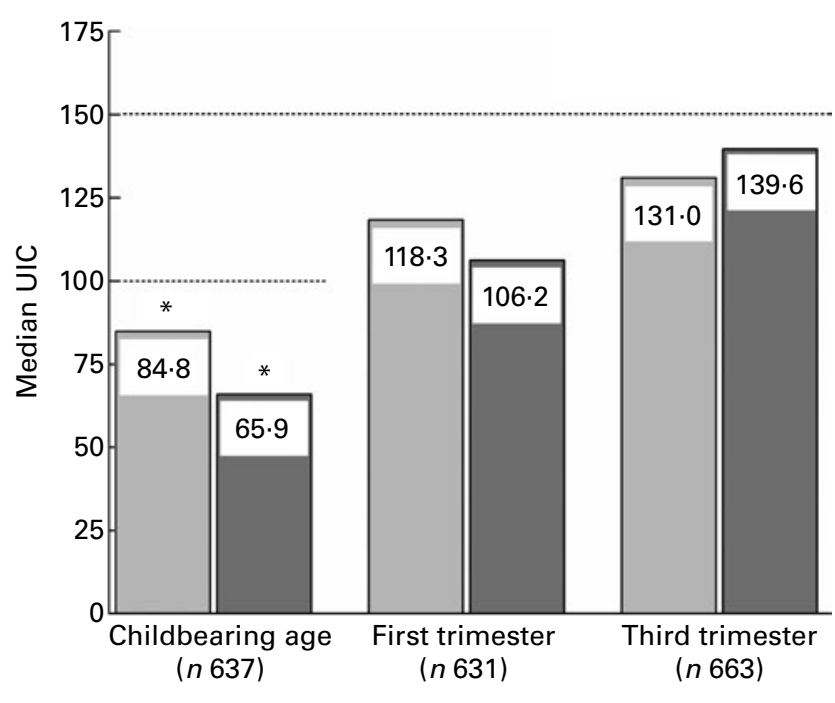

Fig. 2. Median urinary iodine concentration (UIC) (in $\mu \mathrm{g} / \mathrm{l}$ ( $\square$ ) and $\mu \mathrm{g} / \mathrm{g}$ creatinine $(\square)$ ) in women of childbearing age ${ }^{(16)}$ and during the first and third trimester of pregnancy in Belgium. The upper horizontal dotted line represents the lower threshold indicating iodine deficiency in pregnant women $(150 \mu \mathrm{g} / \mathrm{l})$. The lower horizontal dotted line represents the lower threshold indicating iodine deficiency in women of childbearing age $(100 \mu \mathrm{g} / \mathrm{l}) .{ }^{*}$ Median UIC values were significantly different from those of the first and third trimester pregnant women $(P<0.001)$. 
iodised household salt and 1.6\% reported using a combination of iodised and non-iodised salt.

The risk of iodine deficiency was investigated by logistic multivariate analysis (Table 3). The risk of iodine deficiency was significantly higher in younger women, in women not taking iodine-containing supplements and in women consuming milk and dairy drinks less frequently. In addition, the risk of iodine deficiency was significantly higher in autumn compared with winter. When a second model was constructed to asses the risk of iodine deficiency using the UIC values corrected for urinary creatinine, BMI, trimester of pregnancy and alcohol consumption appeared as determinants of iodine status (Table 4). The risk of iodine deficiency was higher in women with a higher BMI and women in the first trimester of pregnancy. Pregnant women who reported alcohol consumption during pregnancy had a lower risk of iodine deficiency (Table 4). Age, use of iodine-containing supplements, milk and dairy drink consumption frequency and season remained as determinants of iodine status in pregnant women as in the first model using uncorrected UIC values.

\section{Discussion}

The present results indicate that pregnant women in Belgium are iodine deficient based on the median UIC, as recommended by the WHO. Although about $60 \%$ of pregnant women reported taking iodine-containing multivitamins during pregnancy, the median UIC did not reach the lower recommended threshold of $150 \mu \mathrm{g} / \mathrm{l}$, indicating iodine sufficiency in pregnant women. More than $50 \%$ of urine samples had a UIC below $150 \mu \mathrm{g} / \mathrm{l}$.

As this is the first national survey on iodine nutrition in Belgian pregnant women, the evolution of iodine status over time cannot be accurately estimated. However, a previous small-scale study in Brussels in 1990 reported a median UIC of $56 \mu \mathrm{g} / 1$ in pregnant women ${ }^{(1)}$. The median UIC reported in the present national survey was $124 \cdot 1 \mu \mathrm{g} / \mathrm{l}$, suggesting that iodine intake in pregnant women has increased over time. However, unlike the population of school-aged children $^{(16)}$, iodine intake remains insufficient in some pregnant women. Other studies have also shown that despite the optimal median UIC in school-aged children, the median UIC in their mothers, in pregnant women or weaning infants may indicate iodine deficiency ${ }^{(23,24)}$.

The median UIC was significantly higher in the third trimester compared with the first trimester or with women of childbearing age. The increase in UIC during pregnancy can be attributed to the intake of iodine-containing supplements. The percentage of women taking iodine-containing supplements was lower in the first trimester than in the third trimester of pregnancy. The failure of iodine supplements to optimise iodine intake in pregnant women stems from the

Table 3. Risk of iodine deficiency during pregnancy in Belgium (urinary iodine concentration (UIC) $<150 \mu \mathrm{g} / \mathrm{l}, n$ 1229)

(Odds ratios and $95 \%$ confidence intervals)

\begin{tabular}{|c|c|c|c|c|c|}
\hline & No. of subjects & No. of women with UIC $<150 \mu \mathrm{g} / \mathrm{l}$ & OR & $95 \% \mathrm{Cl}$ & $P$ for trend \\
\hline Age (years) & & & 0.97 & $0.95,1.00$ & 0.027 \\
\hline Region & & & & & 0.062 \\
\hline Flanders & 632 & 373 & 1 & & \\
\hline Brussels & 213 & 113 & 0.90 & $0.63,1.30$ & \\
\hline Wallonia & 452 & 290 & 1.31 & $1.00,1.71$ & \\
\hline Use of iodine-containing supplements & & & & & $<0.001$ \\
\hline No & 509 & 373 & 1 & & \\
\hline Yes & 788 & 403 & 0.37 & $0.29,0.48$ & \\
\hline Use of salt & & & & & 0.732 \\
\hline Use of non-iodised salt & 1122 & 676 & 1 & & \\
\hline Use of iodised salt & 146 & 89 & $1 \cdot 20$ & $0.82,1.76$ & \\
\hline Use of iodised and non-iodised salt & 21 & 8 & 0.48 & $0.19,1.22$ & \\
\hline Frequency of milk and dairy drink consumption & & & & & $<0.001$ \\
\hline Never & 166 & 112 & 1 & & \\
\hline Less than once per month & 40 & 32 & 1.89 & $0.79,4.50$ & \\
\hline $1-3 d$ per month & 38 & 26 & 1.08 & $0.49,2.40$ & \\
\hline $1 \mathrm{~d}$ per week & 46 & 29 & 0.92 & $0.44,1.92$ & \\
\hline $2-4 d$ per week & 143 & 90 & 0.84 & $0.50,1.39$ & \\
\hline $5-6 \mathrm{~d}$ per week & 50 & 29 & 0.56 & $0.28,1.14$ & \\
\hline Once per d & 655 & 376 & 0.63 & $0.43,0.93$ & \\
\hline Two to three times per $d$ & 139 & 73 & 0.47 & $0.29,0.78$ & \\
\hline More than three times per $d$ & 12 & 6 & 0.34 & $0.10,1.24$ & \\
\hline Ethnicity & & & & & 0.063 \\
\hline White & 954 & 584 & 1 & & \\
\hline Asian & 33 & 11 & 0.36 & $0.17,0.77$ & \\
\hline African (black) & 64 & 36 & 0.78 & $0.45,1.36$ & \\
\hline North African & 173 & 100 & 0.88 & $0.62,1 \cdot 27$ & \\
\hline Hispanic & 12 & 5 & 0.64 & $0 \cdot 19,2 \cdot 16$ & \\
\hline Season & & & & & 0.010 \\
\hline Winter & 469 & 269 & 1 & & \\
\hline Spring & 383 & 225 & 1.02 & $0.76,1.37$ & \\
\hline Summer & 93 & 55 & 1.41 & $0.86,2 \cdot 30$ & \\
\hline Autumn & 350 & 226 & 1.46 & $1.07,1.99$ & \\
\hline
\end{tabular}


Table 4. Risk of iodine deficiency during pregnancy in Belgium (urinary iodine concentration (UIC) $<150 \mu \mathrm{g} / \mathrm{g}$ creatinine, $n$ 1202)

(Odds ratios and $95 \%$ confidence intervals)

\begin{tabular}{|c|c|c|c|c|c|}
\hline & $\begin{array}{l}\text { No. of } \\
\text { subjects }\end{array}$ & $\begin{array}{c}\text { No. of women } \\
\text { with UIC }<150 \mu \mathrm{g} / \mathrm{g} \text { creatinine }\end{array}$ & OR & $95 \% \mathrm{Cl}$ & $\begin{array}{l}P \text { for } \\
\text { trend }\end{array}$ \\
\hline Age (years) & & & 0.90 & $0.86,0.94$ & 0.001 \\
\hline Use of iodine-containing supplements & & & & & $<0.001$ \\
\hline No & 509 & 412 & 1 & & \\
\hline Yes & 788 & 370 & 0.21 & $0.16,0.29$ & \\
\hline Frequency of milk and dairy drink consumption & & & & & $<0.001$ \\
\hline Never & 166 & 108 & 1 & & \\
\hline Less than once per month & 40 & 32 & $2 \cdot 25$ & $0.89,5.72$ & \\
\hline $1-3 d$ per month & 38 & 29 & 2.47 & $0.97,6.27$ & \\
\hline $1 \mathrm{~d}$ per week & 46 & 29 & 0.97 & $0.43,2.17$ & \\
\hline $2-4 \mathrm{~d}$ per week & 143 & 86 & 0.86 & $0.50,1.48$ & \\
\hline $5-6 \mathrm{~d}$ per week & 50 & 30 & 0.73 & $0.33,1.63$ & \\
\hline Once per $\mathrm{d}$ & 655 & 379 & 0.70 & $0.46,1.06$ & \\
\hline Two to three times per $d$ & 139 & 78 & 0.59 & $0.34,1.01$ & \\
\hline More than three times per $d$ & 12 & 7 & 0.60 & $0.15,2.34$ & \\
\hline Ethnicity & & & & & 0.414 \\
\hline White & 954 & 571 & 1 & & \\
\hline Asian & 33 & 11 & 0.32 & $0.13,0.76$ & \\
\hline African (black) & 64 & 40 & 0.77 & $0.41,1.43$ & \\
\hline North African & 173 & 117 & 1.27 & $0.84,1.91$ & \\
\hline Hispanic & 12 & 7 & 1.19 & $0.33,4.24$ & \\
\hline Season & & & & & 0.034 \\
\hline Winter & 469 & 274 & 1 & & \\
\hline Spring & 383 & 228 & 0.91 & $0.65,1.27$ & \\
\hline Summer & 93 & 50 & 1.21 & $0.72,2.03$ & \\
\hline Autumn & 350 & 229 & 1.38 & $0.98,1.94$ & \\
\hline First pregnancy & & & & & $0 \cdot 113$ \\
\hline Yes & 542 & 320 & 1 & & \\
\hline No & 750 & 459 & 0.27 & $0.05,1.42$ & \\
\hline Age $\times$ first pregnancy & & & & & 0.049 \\
\hline Yes & 542 & 320 & 1 & & \\
\hline No & 750 & 459 & 1.06 & $1.00,1.12$ & \\
\hline Trimester & & & & & 0.017 \\
\hline First trimester & 631 & 429 & 1 & & \\
\hline Third trimester & 663 & 351 & 0.73 & $0.55,0.95$ & \\
\hline $\mathrm{BMI}\left(\mathrm{kg} / \mathrm{m}^{2}\right)$ & & & 1.05 & $1.02,1.08$ & 0.001 \\
\hline Alcohol consumption during pregnancy & & & & & 0.033 \\
\hline Yes & 264 & 141 & 1 & & \\
\hline No & 1018 & 635 & 1.51 & $1.07,2 \cdot 12$ & \\
\hline Frequency of fish consumption (fatty fish) & & & & & 0.392 \\
\hline Never & 192 & 136 & 1 & & \\
\hline Less than once per month & 187 & 115 & 0.80 & $0.47,1.34$ & \\
\hline $1-3 d$ per month & 496 & 287 & 0.64 & $0.42,0.99$ & \\
\hline $1 \mathrm{~d}$ per week & 290 & 160 & 0.66 & $0.41,1.07$ & \\
\hline $2-4 \mathrm{~d}$ per week & 112 & 72 & 0.87 & $0.47,1.63$ & \\
\hline Once per d & 10 & 7 & 2.07 & $0.34,12.62$ & \\
\hline Two to three times per $d$ & 2 & 1 & 1.04 & $0.06,18.41$ & \\
\hline Frequency of fish consumption (other fish) & & & & & 0.209 \\
\hline Never & 225 & 152 & 1 & & \\
\hline Less than once per month & 224 & 137 & 0.71 & $0.44,1.14$ & \\
\hline $1-3 d$ per month & 504 & 305 & 1.02 & $0.68,1.53$ & \\
\hline $1 \mathrm{~d}$ per week & 269 & 142 & 0.57 & $0.36,0.90$ & \\
\hline $2-4 d$ per week & 64 & 38 & 0.86 & $0.42,1.74$ & \\
\hline Once per $\mathrm{d}$ & 3 & 2 & 0.28 & $0.01,6.85$ & \\
\hline
\end{tabular}

fact that iodine deficiency was probably present before pregnancy as suggested by the median UIC of $84.8 \mu \mathrm{g} / \mathrm{l}$ in women of childbearing age ${ }^{(16)}$. During pregnancy, the daily thyroid hormone and iodine requirement increases because of the increase in the renal clearance of iodine and because of the transfer of iodine to the fetus, aggravating therefore a preexistent iodine deficiency. There are only a few studies with enough power to classify median UIC by trimester of pregnancy and even fewer studies comparing UIC with UIC of women of childbearing age ${ }^{(25)}$.
In iodine-deficient areas, the median UIC during pregnancy remains constant or even decreases in the absence of iodine-containing supplements ${ }^{(26,27)}$. In areas with iodine sufficiency, the UIC during pregnancy increases and the median UIC is generally above $150 \mu \mathrm{g} / \mathrm{l}^{(28,29)}$. The iodine status in pregnant women in Belgium depicted a situation in which the recommendations to take iodinecontaining supplements work relatively well as UIC are higher in the third trimester of pregnancy. However, because of the inadequate low iodine intake before 
pregnancy, the daily administration of $150 \mu \mathrm{g}$ iodine is not sufficient to reach iodine sufficiency during pregnancy.

This situation illustrates the importance of monitoring the iodine status of pregnant women even when iodine supplements are routinely given to pregnant women.

Many factors may affect urinary iodine excretion during pregnancy. Obviously, the most important is iodine intake and whether or not iodine supplements are given. In the case of iodine sufficiency before pregnancy and in the absence of systematic iodine supplements, median UIC is likely to remain unchanged during pregnancy as suggested by a study from Switzerland ${ }^{(24)}$.

Because glomerular filtration rate increases during pregnancy, the UIC:creatinine ratio, which minimises the variation due to dilution and urine volume, may be more appropriate than UIC expressed as $\mu \mathrm{g} / 1$ to assess iodine intake in pregnant women. However, there are only a few studies comparing UIC:creatinine during pregnancy with a sufficient number of subjects in the first and third trimester of pregnancy to really conclude $^{(30,31)}$. In Belgium, the UIC:creatinine ratio in women of childbearing age and among women in the first trimester of pregnancy was lower than the UIC expressed in $\mu \mathrm{g} / \mathrm{l}$. By contrast, in the third trimester, the UIC:creatinine ratio was higher than the uncorrected UIC. These findings are consistent with a study from an iodine-sufficient area from Japan showing lower median UIC:creatinine during the first trimester and higher during the third trimester compared with UIC not corrected for urinary creatinine ${ }^{(30)}$.

The current iodine status, particularly during early pregnancy, is a matter of concern as most of the women in Belgium are iodine deficient when they become pregnant and they remain deficient during pregnancy, even if the iodine status improves during the third trimester. The exacerbation of iodine deficiency during pregnancy may lead to maternal hypothyroxenaemia and enhanced stimulation of the thyroid gland ${ }^{(32)}$.

Thyroid volume of mildly iodine-deficient pregnant women and their newborn increases during pregnancy as shown in a study performed in Belgium ${ }^{(32)}$ and other European countries $^{(33)}$. In addition, goitrogenesis during pregnancy can be prevented by iodine supplementation during pregnancy ${ }^{(34)}$. Furthermore, brain maturation of the fetus needs thyroid hormones.

However, fetal thyroid secretion occurs only during the second trimester of pregnancy; therefore, maternal thyroxine is the only source of thyroid hormones during the first trimester. Interestingly, several epidemiological studies and some clinical studies have reported an association between intelligence quotient and maternal mild iodine deficiency during pregnancy ${ }^{(35-37)}$.

The median UIC increased with the age of the pregnant women, probably because of the fact that older pregnant women are better informed about food supplements or because of a previous pregnancy. Iodine status was significantly higher in Flanders than in Wallonia based on UIC: creatinine. This finding corroborated a previous study among another Belgian population group ${ }^{(17)}$. The model investigating the risk of iodine deficiency was explained by the use of iodine-containing supplements and the consumption of milk and dairy drinks. Dairy products are the main source of iodine in Belgium as in many other industrialised countries ${ }^{(38)}$. No significant associations were found between an optimal iodine status and fish intake. There were no significant differences in iodine status among pregnant women from different ethnic origin and socio-economic status, as shown previously in Brussels ${ }^{(39)}$.

The risk of iodine deficiency was higher in autumn than in winter as reported in other European countries ${ }^{(40,41)}$. The variation of iodine intake with season has been attributed to variations of the iodine content in milk. During the winter months, cattle are housed indoors and fed with iodinecontaining food.

When the UIC:creatinine ratio was used in the multivariate analysis, all the determinants associated with iodine status in the first model using the uncorrected UIC values remained significantly associated with iodine status. Interestingly, the second model using the UIC:creatinine ratio yielded new determinants of iodine status: BMI and alcohol consumption. Pregnant women who reported alcohol consumption had a lower risk of iodine deficiency. This is the first time that such an association is reported in pregnant women. In a study among adults from Denmark, an association between a reduced prevalence of goitre and solitary nodules and alcohol consumption has been reported ${ }^{(42)}$. Finally, the higher risk of iodine deficiency in women with a higher BMI may also explain the association between thyroid function and BMI in a mildly iodine-deficient area ${ }^{(43)}$.

These associations have not been reported before, probably because this is the first study gathering at the same time enough statistical power, detailed nutritional questionnaires and a correction of UIC for urinary creatinine. Alcohol intake may relate to creatinine or an imprecision of the creatinine correction with a different alcohol intake ${ }^{(44)}$.

The association between BMI and iodine could be caused by differences in creatinine rather than iodine excretion. This is plausible as a higher BMI associates with a higher muscle mass and hence a higher creatinine clearance ${ }^{(45)}$.

The current policy in Belgium to optimise iodine status implemented since 2009 is based on the fortification of bread with iodised salt and the use of iodised table salt. This policy is voluntary and, currently, only $44 \%$ of bread is fortified with iodised salt (source: ESCOSALT). In addition, the use of iodised table salt remains low in Belgium; only $37 \%$ of households use iodised salt ${ }^{(16)}$. The use of iodised salt among pregnant women was even lower, although, in the present survey, the use was self-reported and some misreporting may have occurred. The current voluntary strategy seems, however, to work well for school-aged children as shown previously $^{(16)}$ but not for the adult population. To optimise the iodine status in pregnant women, an increase of iodine intake in women of childbearing age is necessary in order to reach a daily intake of $150 \mu \mathrm{g}$ iodine well before pregnancy. This objective may be reached by increasing the number of bakers using iodised salt in the production of bread and by increasing the utilisation of iodised instead of non-iodised table salt by the general population. 
The study has several limitations. The individual iodine intake could not be determined as only one spot urine sample was collected for each woman. The use of iodised salt among pregnant women was self-reported and no salt sample was collected to determine the iodine content. In addition, although hospitals were selected using a proportionate-to-size stratified sampling design; women in each hospital were included until quotas were reached. Finally, the number of women who refused to participate in the study was not recorded. The main strengths of the study were the nationwide representative sample, the high response rate of hospitals and the fact that women of lower socio-economic classes were not under-represented in the present study as is the case in many other studies.

In conclusion, iodine-containing multivitamins taken during pregnancy increase urinary iodine excretion in Belgian pregnant women, underlying the necessity to promote iodine supplements ideally starting before pregnancy. However, despite the fact that about $60 \%$ of pregnant women reported taking iodine supplements, the median UIC during pregnancy indicated iodine deficiency. Furthermore, some groups of women are at a higher risk of iodine deficiency. The current low iodine intake in women of childbearing age in Belgium precludes the correction of iodine deficiency in pregnant women supplemented with multivitamins containing $150 \mu \mathrm{g}$ iodine as recommended. The iodine status in women of childbearing age needs to be increased in order to meet the iodine requirement during pregnancy. A more generalised use of iodine-containing multivitamins during pregnancy, iodised instead of non-iodised table salt and bread fortified with iodised salt is necessary to optimise the iodine intake in women of childbearing age and in pregnant women.

\section{Acknowledgements}

The authors acknowledge the financial support from the Federal Public Service of Health, Food Chain Safety and Environment. We thank the hospitals and gynaecologists who agreed to participate and all participating pregnant women. The authors would also like to acknowledge B. Hauquier and D. Martin for the urinary iodine determinations. S. V. and R. M.-R. coordinated the study and drafted the manuscript. S. V. performed the statistical analyses. S. A. participated in the fieldwork. All authors contributed to the data interpretation of the results and critically revised the draft versions of the manuscript. The authors declare that there are no conflicts of interest with regard to this study.

\section{References}

1. Glinoer D (1997) The regulation of thyroid function in pregnancy: pathways of endocrine adaptation from physiology to pathology. Endocr Rev 18, 404-433.

2. Haddow JE, Palomaki GE, Allan WC, et al. (1999) Maternal thyroid deficiency during pregnancy and subsequent neuropsychological development of the child. $N$ Engl $J$ Med 341, 549-555.

3. Pop VJ, Kuijpens JL, van Baar AL, et al. (1999) Low maternal free thyroxine concentrations during early pregnancy are associated with impaired psychomotor development in infancy. Clin Endocrinol (Oxf) 50, 149-155.

4. Zimmermann MB (2011) The role of iodine in human growth and development. Semin Cell Dev Biol 22, 645-652.

5. Zimmermann MB (2009) Iodine deficiency in pregnancy and the effects of maternal iodine supplementation on the offspring: a review. Am J Clin Nutr 89, 668S-672S.

6. Gordon RC, Rose MC, Skeaff SA, et al. (2009) Iodine supplementation improves cognition in mildly iodine-deficient children. Am J Clin Nutr 90, 1264-1271.

7. World Health Organization and UNICEF (2007) Iodine Deficiency in Europe: A Continuing Public Health Problem. Geneva: World Health Organization.

8. De Benoist B, McLean E, Andersson M, et al. (2008) Iodine deficiency in 2007: global progress since 2003. Food Nutr Bull 29, 195-202.

9. WHO/UNICEF/ICCIDD (1994) Indicators for Assessing Iodine Deficiency Disorders and Their Control Through Salt Iodization. WHO/NUT/94.6. Geneva: World Health Organization.

10. Zimmermann MB \& Andersson M (2011) Prevalence of iodine deficiency in Europe in 2010. Ann Endocrinol (Paris) 72, 164-166.

11. Vanderpump MP, Lazarus JH, Smyth PP, et al. (2011) Iodine status of UK schoolgirls: a cross-sectional survey. Lancet 377, 2007-2012.

12. Vandevijvere S, Annemans L, Van Oyen H, et al. (2010) Projected reduction in healthcare costs in Belgium after optimization of iodine intake: impact on costs related to thyroid nodular disease. Thyroid 20, 1301-1306.

13. Delange F, Van Onderbergen A, Shabana W, et al. (2000) Silent iodine prophylaxis in Western Europe only partly corrects iodine deficiency; the case of Belgium. Eur J Endocrinol 143, 189-196.

14. Ciardelli R, Haumont D, Gnat D, et al. (2002) The nutritional iodine supply of Belgian neonates is still insufficient. Eur J Pediatr 161, 519-523.

15. Moreno-Reyes R, Van OH \& Vandevijvere S (2011) Optimization of iodine intake in Belgium. Ann Endocrinol (Paris) 72, 158-161.

16. Vandevijvere S, Mourri AB, Amsalkhir S, et al. (2012) Fortification of bread with iodised salt corrects iodine deficiency in school-aged children but not in their mothers: results from a national cross-sectional survey in Belgium. Thyroid (epublication ahead of print version 18 June 2012).

17. Vandevijvere S, Dramaix M \& Moreno-Reyes R (2011) Does a small difference in iodine status among children in two regions of Belgium translate into a different prevalence of thyroid nodular diseases in adults? Eur J Nutr 51, 477-482.

18. Brull L \& Dewart L (1956) Répartition et fréquence du goitre chez les recrues en Belgique (Distribution and prevalence of goitre among recruits in Belgium). Rev Med Liege 11, 653-656.

19. Sullivan KM MSMG (2000) Urinary Iodine Assessment: A Manual on Survey and Laboratory Methods. Atlanta, GA: UNICEF/PAMM.

20. Pino S, Fang SL \& Braverman LE (1996) Ammonium persulfate: a safe alternative oxidizing reagent for measuring urinary iodine. Clin Chem 42, 239-243.

21. Caldwell KL, Makhmudov A, Jones RL, et al. (2005) EQUIP: a worldwide program to ensure the quality of urinary iodine procedures. Accred Qual Assur 10, 356-361.

22. Hervey GR (1953) Determination of creatinine by the Jaffe reaction. Nature 171, 1125.

23. Gowachirapant S, Winichagoon P, Wyss L, et al. (2009) Urinary iodine concentrations indicate iodine deficiency in pregnant Thai women but iodine sufficiency in their school-aged children. J Nutr 139, 1169-1172. 
24. Andersson M, Aeberli I, Wust N, et al. (2010) The Swiss iodized salt program provides adequate iodine for school children and pregnant women, but weaning infants not receiving iodine-containing complementary foods as well as their mothers are iodine deficient. J Clin Endocrinol Metab 95, 5217-5224.

25. Zimmermann MB (2007) The impact of iodised salt or iodine supplements on iodine status during pregnancy, lactation and infancy. Public Health Nutr 10, 1584-1595.

26. Limbert E, Prazeres S, Sao PM, et al. (2010) Iodine intake in Portuguese pregnant women: results of a countrywide study. Eur J Endocrinol 163, 631-635.

27. Stilwell G, Reynolds PJ, Parameswaran V, et al. (2008) The influence of gestational stage on urinary iodine excretion in pregnancy. J Clin Endocrinol Metab 93, 1737-1742.

28. Hollowell JG, Staehling NW, Hannon WH, et al. (1998) Iodine nutrition in the United States. Trends and public health implications: iodine excretion data from National Health and Nutrition Examination Surveys I and III (1971-1974 and 1988-1994). J Clin Endocrinol Metab 83, 3401-3408.

29. Caldwell KL, Jones R \& Hollowell JG (2005) Urinary iodine concentration: United States National Health and Nutrition Examination Survey 2001-2002. Thyroid 15, 692-699.

30. Fuse Y, Ohashi T, Yamaguchi S, et al. (2011) Iodine status of pregnant and postpartum Japanese women: effect of iodine intake on maternal and neonatal thyroid function in an iodine-sufficient area. J Clin Endocrinol Metab 96, 3846-3854.

31. Brander L, Als C, Buess H, et al. (2003) Urinary iodine concentration during pregnancy in an area of unstable dietary iodine intake in Switzerland. J Endocrinol Invest 26, 389-396.

32. Glinoer D, De NP, Bourdoux P, et al. (1990) Regulation of maternal thyroid during pregnancy. J Clin Endocrinol Metab 71, 276-287.

33. Smyth PP, Wijeyaratne CN, Kaluarachi WN, et al. (2005) Sequential studies on thyroid antibodies during pregnancy. Thyroid 15, 474-477.

34. Glinoer D, De NP, Delange F, et al. (1995) A randomized trial for the treatment of mild iodine deficiency during pregnancy: maternal and neonatal effects. I Clin Endocrinol Metab 80, 258-269.
35. Azizi F, Afkhami M, Sarshar A, et al. (2001) Effects of transient neonatal hyperthyrotropinemia on intellectual quotient and psychomotor performance. Int J Vitam Nutr Res $\mathbf{7 1}$, $70-73$.

36. Calaciura F, Mendorla G, Distefano M, et al. (1995) Childhood IQ measurements in infants with transient congenital hypothyroidism. Clin Endocrinol (Oxf) 43, 473-477.

37. Vermiglio F, Lo Presti V, Moleti M, et al. (2004) Attention deficit and hyperactivity disorders in the offspring of mothers exposed to mild-moderate iodine deficiency: a possible novel iodine deficiency disorder in developed countries. $J$ Clin Endocrinol Metab 89, 6054-6060.

38. Vandevijvere S, Lin Yi, Moreno-Reyes R, et al. (2012) Simulation of total dietary iodine intake in Flemish preschool children. Br J Nutr 108, 527-535.

39. Moreno-Reyes R, Carpentier YA, Macours P, et al. (2011) Seasons but not ethnicity influence urinary iodine concentrations in Belgian adults. Eur J Nutr 50, 285-290.

40. Nawoor Z, Burns R, Smith DF, et al. (2006) Iodine intake in pregnancy in Ireland - a cause for concern? Ir J Med Sci $\mathbf{1 7 5}$, $21-24$.

41. Als C, Haldimann M, Burgi E, et al. (2003) Swiss pilot study of individual seasonal fluctuations of urinary iodine concentration over two years: is age-dependency linked to the major source of dietary iodine? Eur J Clin Nutr 57, 636-646.

42. Knudsen N, Bulow I, Laurberg P, et al. (2001) Alcohol consumption is associated with reduced prevalence of goitre and solitary thyroid nodules. Clin Endocrinol (Oxf) 55, 41-46.

43. Knudsen N, Laurberg P, Rasmussen LB, et al. (2005) Small differences in thyroid function may be important for body mass index and the occurrence of obesity in the population. $J$ Clin Endocrinol Metab 90, 4019-4024.

44. Chung FM, Yang YH, Shieh TY, et al. (2005) Effect of alcohol consumption on estimated glomerular filtration rate and creatinine clearance rate. Nephrol Dial Transplant 20, $1610-1616$

45. Gerchman F, Tong J, Utzschneider KM, et al. (2009) Body mass index is associated with increased creatinine clearance by a mechanism independent of body fat distribution. J Clin Endocrinol Metab 94, 3781-3788. 